Lingua 21 (1968) 41-54, (O) North-Holland Publishing Co., Amsteriam Not to be repronuced by photoprint or microfiln without written permission from the publisher

\title{
THE SOUNDS OF SIPEEGH: SEGMENTS OR FIGMENTS?
}

\author{
A. $\mathrm{COHEN}$
}

An electron is not a fiction anymore than .. gravity (is). They are all real: that is, their behavior is real in the sense that it can be described, its implications are real in thie sense that they can be forecast, and its con. sequences are real in the robust sense that they can be observed. We have the right therefore to say, if we choose, that an elec. tron is a real thing - but wo would be foolish to exercise that right, because it would place on us the duty to disentangle our use of the word thing here from its everyday use.'

J. Brorlowski, The Identity of $\operatorname{Man}$ (39).

The title has been chosen to restate a time-honoured controversy in linguistics, the relation of phonetics to phonemics, in a more modern and, it is hoped, less confusing fashion. The reason for this attempt at revivifying interest in an apparently outmoded problem is the following consideration. Modern phonetic studies, using new techriques including synthetic, artificial speech, have run up against problems whose solution will require a new look at phonemic post. 1 . lates. If this requirement is to be fulfill st will undoubtedly have strong repercussions for phonemic theory in general. The main ain of th is article will be to focus attention on a very crucial point whose intrinsic interest will affect work carried out by investigators in different and diverse disciplines, thus constituting a methodological problem of wider range and of more than parochial interest to lir. guists, viz. the problem of segmentation, of analysing the object ol investigation into relevant units whose synthesis would reconstitute the original ensemble.

For the sake of clarity the following sections will deal seprately 
with what is traditionally called phonemic ar alysis, and phonetic analysis. The tenor of the total contritution will be that both pursuits, phonetics and phonemics, having to do with sounds of speech must needs come to terms with the question of what they regard these to be. In technical journals supplying information on studies dealing with synthetic speech and automatic speech recognition the terms 'phonernic' and 'phonetic' are not clearly distin guished; thus one may come across descriptions of similar apparatus figuring under such headings as 'phoneme recog jiser' and 'phonetic i.ypewriter' used indiscriminately. Part of the ta: $\mathrm{k} I$ have set myself will be to find extenuating circumstances that may explain how this confusion has come about, without necessarily blaming or exculpotting any persons or any one discipline but rather in an effort to draw attention to a possible renewal of interest in and a reformulation of the problen of common interest to all th ose concerned with speech phenomena.

\section{Traditional phonemics}

From an historical point of view it would be fair to state that phonemics arose as a special discipline within the larger field of linguistics proper. As a convenient start we may choose 1928 , the year in which the First Internationa Congress of Linguists was held at The Hague. $\left.{ }^{1}\right)$ The driving force in this new linguistic c.wakening was the dissatisfaction of linguists with the methods of jhonetics, notably expenmental phonetics, which seemed to imply a f ernicious stressing of the diversity, if not chaotic character of the sounds of speech when measured accurately. There seemed to be more differences than correspondences between sounds that one would irituitively prefer to call the same. In Man's World of Sound (Pierce and David, 1958: 92-93), examples are given to show how dififunii it is to tell from an inspection of oscillographic recordings which sounds should be considered similar, to the effert that at times there seems to be better correspor dence between different sounds of two speakers than between 'sames'.

It was obvious that linguists were appalled at this state of things, trained as they were to describe what is systematic in the act of

1) For a more cetailed account dealing with the forerunners of what she calls the 'Phonologrical epoch in Linguistics', of. Milka Ivix (1965: Ch. 15). 
speech and as such belonging to the system of languagc. As a correction to the apparently chaotic state of phonetic knowledge they introduced the nution of semantic differentiation, of distinctiveness. Thanks to this concept they were able to convince themselves that it was possible, after all, to consider wide variations among speech sounds as realisations of a limited number of classes, phonernes.

If one reads through the Proceedings of this congress one cannot help feeling that very little has changed since 1528. This in itself need cause no alarm nor indicate that the phonemic frame of reference is inapplicaule, but it does warrant calling the phonemic approach isased on distinctivity traditional phonemics. As ran be found in proposition 22: 'Toute description scientitique dle la phonologie d'une langue doit avant tout comprendre la charactéristique de soi système phonologique, c.-à-d. la charactéristique du repertoire, propre à cette langue, des différences significatives en tre Jes images acoustico-motrices'. (Actes, 1928: 33). Objections were raised right away against the term acoustico-motoric as being psychologistic or mentalistic. It was quickly dropped in later versions.

The operative term in this preamble to the principles of phonemic classification is 'significant'.

As for this notion of signilicant difference, it will suffice for the present to state that it has proved extremely useful in linguistic description, where the main aim of linguists has been to set up inventories of linguistic forms and their interrelations according to certair classificatory principles which are generally designated as paradigmatic and syntagmatic, a distinction introduced by $\mathrm{Hj} \mathrm{clins-}$ lev clearly echoing de Satussurc.'s earlier observation in distinguishing 'rapports associatives' frora 'rapports syntagmatiques' (cf. Ivič, 1965: 182).

What seemed to have been uppermost in the minds of those linguists who rallied to the cause of the phonemicists, is that they were able to make use of the phonemic principle in an effort to portra; the behaviour of language users as if guided by the phonemic rules laid bare by the linguists.

R. Jakobson, one of the signers of the call in 1928, has always striven to make clear that the i.ird of differentiation postulated by linguists is actually at work at the stage of language acquisition by children. He hypothesized, that certain basic distinctions, as be- 
tweer: $/ p /$ and $/ a /$, are not only found in all languages but are also the first learneủ by children (Jakobsen and Halle, 1956: 37).

If we take a jump over the decades into the fifties we will find that much the same principle of distinctiveness is still the leading principle of a good deal of phrnemic description.

As Hockett concisely puts is (echoing, no doubt deliberately, an earlier statenent by Bloomfieid) 'The fundamental assumption in phonology is that, despite wide variation of actual articulatory motion from one speech-event to another in a community, the speakers of a lang'iage themselves hear some speech-events as the same, some as different' (Manual: 144). One may notice that in fact an even largter afplication has been given to this notion to the extent that the so-called distinctive features are the logical outcome of such a procedure. Not only were words, or morphemes, in short: iinguistic forms, sufficiently characterised in being distinguishable from all other formis, with the exception of homonyms, but also phonemes could be described and arranged in such a way as to be differentia ed by as few distinguishing characteristics as was possible (cf. Jakobson et al. 19:52: 7).

One basic advance in phonemic theory is mainly due to the work of American linguists on the subject of distributional criteria for phonernic specification. This approach seeks to show that no two phonemes ever show exactly the same positions within linguistic forms, and thus can be considered to be sufficiently distinguished and characterised on the strength of privileges and constraints of occlirrence. ${ }^{2}$ )

In fact, the two principies of classification, based on oppositional and distributiomal criteria fall in line with the more general guiding principles of arrangement along the po adigmatic and syitagmatic axes. $\left.{ }^{3}\right)$

2) An early example of such a distributionai classification of phonemes is given by Bloonfield (1933: ch. 8). The primacy of distributional criteria fo: finding and describing phonemes is maintained by Harris (1951) throughoul inis Methods in structural iinguistics. A more modern version of the application of the distributional principle is to be found in Householder (1962).

3) A further distinction is some im 's made between oppositions, significant difterences within one paradigm, :.e. $v$ ithin the same environment, and 'contrasts', similar differences but only occurring in different environments. An example of the first is the oppositior between $/ \mathrm{p} /$ and $/ \mathrm{b} /$ in pin and bix, and of contrast between $/ \mathrm{p} /$ and $/ \mathrm{a} /$ in $p a$ (see e.g. Jak bson and Halle, 1956: 4). 
In general, all phonemicising presupposes a previous representation of linguistic material in terras of a phonetic specification. Such a representation should re veal the linguistic system in so far as it can be seen to be reflected in the speech forms used by native speakers and interpretable by nativ s listeners, who often act as informants to the linguist. This is notably the case in so-called fieldwork, where the investigator does not necessarily have any previous knowledge of the language under analysis. In othe: words, phonemic analysis under this aspect came to assume very much the character $v i$ a skill, a technique that could be learnt is a kind of drill, witness the undertitle of Pike's classical work in th. ic ficld, Phonemics: A technique for reducing langzuges to writing (1947). A similar pragmatic spirit pervades Hockett's Manual of Phonology (1955).

It may be worth while to observe that it is generally the linguists themselves who acted as phoneticians in their task of collecting speesh material for subsequent analysis within a linguistic frame of reference. This observation, however trivic 1 it may secm, is nevertheless necessary to account for the othervise incredible cc nfusion that has reigned ever since Trubetzkoy's Grundziige (1939, if not indeed earlier, about the conflicting aims and methods of phonetics and phonemics. If indeed the linguist is dependent on reliable speech material as the basis of his phonemic investigations, it seems wholly unwarranted to expect any serious clearage between the two disciplines.

In retrospect, however, it becomes clear that by phonetics Trubetzkoy in one context meant language oriented phonetics, whereas in another context he had in mind what was variously called instrumental or experiment il phonetics, which he rangcd among the natural sciences and which could therefore not be, in any direct sense, of value to linguistics, a branch of the humanities. He wished to distinguish clearly between the study of speech sounds (jarcle) and that of language sounds (langue), (Principes de Phonologie: $9 \mathrm{ff}$ ).

At this point we may, rerhaps, leave traditional phonemics by quoting Hockett's concise statement that 'Phonological analysis, then, is concerned with the way in which utterances, under ideal hearing conditions, are kept apart by virtu? of acoustic ${ }^{4}$ ) evidence

4) The use of the term 'acoustic' in a non-technical sense (unlike section 2, below, where it is used differently) has probably given rise to the coniusion referred to above. Hockett clearly means 'auditory' hcre and so did Trubetz- 
and it alone' (Hockett 1955: 145). It seems time to turr to this type of evidence and to see what we can learn from it.

\section{Acoustic phonetics}

Contrary to the phonemic discipline, which originated from the work of linguists who took the sign character of language for granted, most studies in the foid if acoustic phonetics have originate i from people whose acquaintance with linguistics will at best have been of the nodding kind. The main impetus given to it was due to the work of telephone engineers and more generally of those working in the field of speech communication. In this area it has long been known that not all physical information present in the acoustic waves is of equal importance to language users when speaking over a telephone link. The main practical aim of those responsible for the design and maiintenance of telephone transmission lines has been to guarantee on the one hand acceptable quality, in terms of intelligibility and naturalness, and economic efficiency on the other, i.e. getting rid of whatever part of the speech signals that was not obviously conducive to the factor of quality. This resulted in various techniques of so-called speech bandwidth compression.

In ord $r$ to describe the various distortions that could be introduced to si eech messages before the quality seriousiy deteriorated, use was made of a rough and ready notation of the original speech material very much on the lines of a phonetic transcription. If one turns, for instance, to one of the standard works in this field, Speech and Hearing (1) tcher, 1929), reissued in 1953 in a new edition entitleu Speech and Hearing in Communication, it will be noticed that the very first chapter deals with 'The speech sounds of English', of which there are saic to be 39 which vere determined on the following criteria: the manner of formation, physical characteristics and 'particularly the aver'ige listener's auditory ability to discriminate among them' (ed. 's53: 1).

This approach, therefore, makes no bones about interpreting, or at least describing, the continuous speech waves in terms of a series of individual (distiactive) speech sounds. The justification for the latter is or has been for long the main pursuit of phonemic studies.

koy when describing : he work of the phonemicist in discovering distinctive acoustic differences (Crurdzìge: 17, Principes: 15). 
Orce the communications engineer has helped himself on a purely pragmatic basis to a labelling device derived from practical phonetics, $\left.{ }^{5}\right)$ he is at liberty to describe speech messages in terms of pressure variations as a function of time. He is no longer concerned with deriving from these physical phenomena, air vibrations, anything like speech sounds, let alone phonemes. He is always at literty to check whether the wave patterns inderd constitute intelligible speech. The transformation he cdopts for the purpose of studying the air pressure variations is usually a visual display in terms of an oscillographic recording. Now one of the vital points about acoustic phonetics is that most workers in this field are quite satisfied to portray original speech messages in a visual shape. All complex vibrations can mathematically be described in terms of the so-called Fourier transform, which results in an ultimate analysis of simple frequencies called sinusoids. With the help of electric filters such an analysis inay also be made visible, resulting in the portrayal of the spectrum of the sound under a alysis. It is on this very principle that the spectrograph is based, having the added advantage that it also gives some indication of the various intensities involved in the sound waves.

Now all these and similar techniques do not pretend to establish correiations between physical entities and linguistic units. Nevertheless, with the help of the rough and ready division of the speech continuum into individual speech sourds it is possible for the acoustic phonetician to give a specification in terms of physical preperties for each speech scund, and for classes of sounds which have sume properties in common.

One of the methods employed to arrive at such a specification is to range speech sounds in frames of, say, the CVC type, which are generally chosen in such a way that the number of sounds occurring in a list of frames of this type reflects their frequency of occurrence in connected speech.

$\mathrm{CVC}$ structures have triditionally been composed so as to form nonsense words in an effort to objectivate measurements calculated to establish the so-called articulation index, i.e. an evaluation of the quality of a speech link. From a strictly linguistic standpoint such nonsense forms are not words at all and should not be used, at

5) Bioomfield's term for the study of significant speech sounds (1933: 78). 
least, if one woul 1 insist on taking the distinctiveness criterion seriously. In fact, consense words would not normally be regarder to be linguistic f $m$ ms at all! Nevertheless, in actual practicc they have prcved to bo quite handy for the purpose for which they were designed.

It has always been recognised, at least in this field of rescarch, having to do with acoustic wave patterns, that there are hardly any 'steady-states' and no clear dernarcations between one segment and the next. Nevertheless, the concept of segmentation, derived from linguistics, is a very powerful one and workers in this field are loath to dispense with it.

Increasingly, insight is being gained into the special phenomenon of speech, that only by knowing the total pattern, word forms, and even larger language structures, is it at all possible to conclude about the building blocks, the linguistic subunits, the phonemes. One has to know the language to be able to interpret correctly, or at least adequately, the speech waves offered as a continuum. This goes both for the naive languare user and for the investigator.

The main difference of approach between 'pure' phonemicists and 'pure' phoneticians seems to reside in the fact that the former have erolved a method, a technique, enabling them to make shrewd guesses as to the linguistic structure of language that they do not need to know completely, whereas the speech communications engineer takes his knowledge of the language for granted and is at pains to test how much speech quality may suffer before it becomes unacceptable.

In phonemic studies, the linguist tries to be as economical as possible in choosing the number of elements to help him out in describing the phonemic inventory, and, in showing the structural relatinns obtaining among them, he is once more economizing on the necessary attributes to keep one phoneme distinct from any other.

That phonemes as such can be recognised is taken for granted by the linguist; he is cnly concerned with showing in what respect they differ. For the phonctician, speech sounds are obviously different but he would very much like to have a clue as to the way in which, for the purpose of speech communication, various differences of 'same' speech sounds might be exploited by treating them as physical sames. 
A similar problem has seen formulated as a quest for invariants of speech. By simply studying the physical features, frequencies, intensities, etc. as found in the various forms of recording the acoustic wave patterns, such invariants have not been and will not be found. ${ }^{6}$ )

The introduction of instruments that produce artificial speechlike patterns which will have to be evaluated by listeners knowing the language aimed at, constitutes the main hope of overcoming this predicament. The newest insight into the whole process of speech communication teaches us that we have two systems to regard: the physical phenomena that constitute the speech continuum and the perceptual mechanism which forms the link between language as a systrm in the abstract and the accustic phenomena (cf. Cohen 1967: 324).

Now general phonetics in the past may have laid itself open to the abjection that it studied the instrument provided by the human vocal tract not necessarily in conjunction with the use made of it by any particular language community. One of the most consistent studies in this field is the wellinnown book Phonetics by K. L. Pike (1943), who went out of his way to accommoda te coughs and sneezes, as well as vowels and consonants, since they could all of them be produced by this one instrument, the human vocal tract.

One may raise similar objections to the acoustician who is happy in portraying the various patterns recorded by his registering apparatus, whenever someone is speaking.

But the major advantage in modern experimental phonetics is that a!: those engaged in this field know beforehand that they are dealing iitier directly or at some remove, depending on whether they study spontaneous or laboratory-concitioned speech, with products of language structure that were or could be supposed to have been created by language users and destined to be interpreted by them.

With the new instruments, notably the spee in synthesisers, it has become possible to test hypotheses about the character of language

6) E.j. in the words of the Haskins group of researchers 'A finding which turns uf over and over again in 2 variety of different, yet reliated forms is that there is a complex relation between perceived language and the acoustic signal which conveys it. Nore specifically, the acoustic signal is quite commonly not invariant with respect to the phoneme as parceived'. (Liberman et al., 1967: 74). 
structures as manifested in speech waves. The recording instruments will merely function as objective means to register the acoustic character of the sound waves under investigation. As such, they simply adduce data for the time-honoured method of using a phonetic transcription as a labelling device. The real analysis, as in the case of practical phonetics, is carried out by listeners familiar with the language in question.

This throws the whole burden of proving the fasibility of breaking up the speech continuum, whether of a known or urknown language, clearly on the perceptual mechanism of the analyser. That such a procedure is feasible is proved by the worldwide and longstanding success of the alphabetical tradition in writing. More recently new support has been provided by linguistically trained field workers who set out to take down hitherto unknown languages, by recording them in a phonemic system of writing. What the phonetic typewriter, in instrument under construction and still very much in the exper mental phase, is alleged to carry out on its completion is io do just that, copying, in other words, the work of trained linguists. 13ut, and this is the main and apparently insurmountable stumbling block in this approach, the initial division of the speech continuum, the relegation of long stretches of speech to series of individual, segmented speech sound: cannot be carried out by purely physical means. There are no hard and fast demarcation lines between what phonemicists like to consider separate, discrete 'entities. The 'phoneme recogniser' - the term is used for exactly the same generic type of instrument as the phonetic typewriter, actually constituting but one stage of it and by far the most critical one - suggests by its name a more rewarding approach to this very same prcblem, viz. of coming up eventually with the same discrete entities that are the hall-mark of phonemic analysis.

It is time we tried to clear up this confusion in a final section devoted to sketching to what extent the most recent insights in either field, of linguistics and acoustic phonetics, can be used for mutua: benefit.

\section{Sounds and features}

Recent linguistic studies, particularly those that are influenced by the transformational approach, have resulted in a very pronounced shift in the attention of linguists away from a phonemic 
primacy towards a syntactic one. In such an approach the existence of large stretches is taken for granted, and the type of phonemic description to be used is dependent on a previous operation on higher linguistic levels, syntactic structures. Yet the sound character of the ultimate units of description is still adhered to, witness the title of an important prospective work in this area of inguistic studies 'The sound pattern of English', (Chomsky and Halle, in press). ${ }^{7)}$ However, it seems fair to summarise the devesopment of the nature of the erstwh ile 'distinctive features', as coined by Jakobson, by stating that tney have moved away from being acoustic attributes - derivable from a close inspection of the spectrographic recordings - a view still prevalent in Preliminaries (Jakobson et al. 1952 ) in the direction of abstract constructs invented for the converience of linguistic analysis (Stevens and Halle, 1967). ${ }^{8}$ )

The upshot of this development is that phonemics has come of age to the extent that a justification for seemingly arbitrary discovery procedures is no longer required. By the same token, such a tortuous phonemic description need no longer provide the basis for subseqrent treatment of higher linguistic levels. In dealing with utterances, modern linguists may feel safe in honouring the sound character of their object of investigation. They arc, howe ver, relicved of the burden of har ing to prove that the ultimate units of description, the distinctive features, slonid still in all respects be ass amed to have the character of physical entities. This development ties up very well wi h a similar one apparent in acoustic phonetic studies where the view of the sounds of speech as ope1ationally retrievable segmerits of the utterance by purely physical

7) In choosing this term sound pattern' the authors reflect the work of Sapir (19:1, 1925). Thus e.g. 'Back of the purely objective system of sounds that is peouliar to a language .. there is a more restricted 'iuner' or 'ideal' system, which, while perhaps equally unconscious to the naïve speakt $r$, can f.i.r more readily be brough to $l$ is consciousness as a finished pattern, a p.iychological mechanism'. (Sapir, 1921: 55).

8) '. characterizations of speech in terms of segments or features are not more or less naturalistic records of particular physical events but are rather alistract representations of classes of events.' (Stevens and Halle, 1967: 90) and again '. . it cannot be expected that the underlying representation should in all cases be recoverable from the [acoustic] signal by simple techniques of signal analysis' (ib. 94). 
means is rapidly losing adherents. It is only in rare ant specifiable cases that we are called upon as users of the languare to decide about the character of a single phoneme, corresponding to a single sound of speech. V/then the need arises we are capable of performing this trick but it is a longer held to be the most characteristic ispect of our activity in dealing with speech as ordinary users of the language. The fate of poorly un erstood proper names testifies to the clearly present limitations of the peiceptual mechanism when left to its own purely phonemic resuurces. From the point of view of wo kers in the field of acoustic phonetics one may observe that there is more to the speech message than meets the eye in a registrograin; there is the implicit knowledge of the rules of the language cot wich is an indispensable help in the task of segmenting the sc-called sounds of speech. Looking at the same speech message from a linguistic point of view a similar observation may be made. In attempting to account for the behaviour of the language user in interpreting the message, a purely phonemic approach will not suffice. We do not ordinarily recognise and understand speech solely in terms of its phonemic make-up. The phonemic structure of a particular language is only part of the knowledge the language user brings to bear upon tine task of understanding speech (cf. e.g. Miller and Isard 1963). To admit that phonemes are hypothetical constructs, even to the extent of constituting abstract notions, need not invalidate their claim of being legitimate tools of the linguist's trade. It certainly helps to make the notion of speech sounds more respectable. I hope to have made clear that they too derive their existence from an operational procedure, very similar to the one responsible for establishing phonemic units.

In conclusion, then, it seems warranted to state that in studying speech there is a strong theoretical basis for the principle of segmentation, underlying the notion 'speech sounds'. The role they play in the act of speech communication can be accounted for by applying experimental means. In this way, once the results of linguistic descriptional devices have been explicitly formulated in terms of testable hypothese., the behaviour of language users can be studied in a 1uuch wider framework. ${ }^{9}$ ) In such a futare study, segments,

9) Cf. Vischek (1966: 4: 43) on the restrictions of Wortphonologie and Filch (1964:24-28) on the nsatisfactory treatment of juncture phenomena to counterbalance these limit. s.s. 
larger than phoneme size can be po:tulated and checked in in effort to crack the speech code, i.e. the inupicit knowledge speakers and listeners bring to bear in respectiveiy producing and interpreting speech.

Engels Seminarium, University of Utrecht, Utrocht, The Netherlands

\section{R.EFERENCES}

Artes alu Premier Congres laternational de Linguisies, 1928. Leiden, 1. 11. Sijthoff.

BLoovirierd, L., 1933. Language. Loncion, Allen $\&$ Unwin T.td.

CoHFv, A., 1967. 'Speech, percepts, and linguistic forms'. In: W. WathenDunn, Models for the perception of speech and risual form. ed., Cambridge. T.I.T. Press. 320-325.

Fletcher, H., 1953. Speech and hearing in communication. New York. I. van Nostrand Cy., Inc.

HARRis, Zellig, S., 1951. Methods in structural linguistics. Un. of Chicago Press,

HocketT, C. F., 1955. A mantul of phonology. Baltimore, Waverly Pist. Inc.

Housarolder, F. W., 190?. 'The distributionai determination if Englist: phonemes', Lingua 12, lis-191.

Ivic, M., 1965. Trends an linguistics. The Hag(1:. Mouton \& C..).

Jakofison, R., S. Karcheysicy, N. Trubetskoy, 1928. 'J'roposition 22', Acte's du Premier Congrès de Linguistes, ieiclen, A. W. Sijthoff, 33 ff.

Jaroesson, R., C. G. M. FAnt and M. Halle, 1952. Preiminaries to speeth analysis. Cambridge, M.I.T. Press.

ilberman, A. M., F. S. Cooper, K. S. Harris, P. F. Mac Nisilage, and M. StudDerT-KenNedy, 1967. 'Some observations on a model for speech perception', $I_{1}$ : W. Wathen-Dumn, ed., Models for the perception of speech and visual forn, Cambridge, M.I.T. Press. 68-87.

Miller G. A., and S. ISARD, 1963. 'Some perceptual corseguences of linguistic rules'. J. of Verbal Learn, and V. Beh., 2, 217-224.

Pierce, J R., and E. E. David, Jr., 1958. Man's world of solind. Niew Sirti, Doublec ay \& Co., Inc.

Fike, K. 1.., 1943. Phonetics. Anr Arbor, Un. of Michigan !ress.

Fike, K. 1., 1947. Phonemics. Ann Arbor. Un. of Michigan Press.

Pilch, H., 1964. Phonemtheorie, I. Teil Batei-New York, S. Karger.

SAPIR, E., 921. Language. New York, Harcourt, Brace anc Comp.

SAPIR, E., 1925. 'Souad patterns in languay,e', Lg 1, 37-51. (A so in: Martin Joos, ed. 1758. Readings in linguistics. I ew York, A.C.1. S., 19-25). 
Stevens, K. S. and M. Halle, 1967. 'Remarks on analysis by synthesis and distinctive features' In: W. Wathen-Dunn, ed., Models for the perception of speech and visual form. M.I.T. Hress 88-102.

Truberzkoy, N. S., 1939. Grundzüge der Phonologie, T.C.L.P., VII, Prague. Translated by J. Cantineau, 1749, Principes de Phonologie. Paris, Klincksis ck.

Vacrek, J., 196.J. The Linguist'c Schosl of Pragus. Ch. III 'Problems of Plonology', Intiana Un. Press. 